\title{
O Instituto de Química em 1994
}

\section{WALTER COLLI}

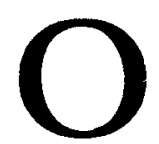

Instituto de Química da Universidade de São Paulo - IQUSP

- foi formalmente constituído em 1970, em decorrência da reforma universitária. No entanto, já em 1966, haviam-se transferido para as novas dependências da Cidade Universitária todos os Departamentos, Cadeiras e Disciplinas de Química e Bioquímica e algumas afins pertencentes a seis Faculdades distintas. Esse fato, bastante significativo, mostrou que, antes da obrigatoriedade determinada pela legislaçáo, alguns setores da Universidade já reconheciam a importância de aproximar grupos com objetivos idênticos mas dispersos pela cidade de São Paulo.

Constituiu-se o Instituto com dois Departamentos: o de Química Fundamental e o de Bioquímica. Para a formaçáo do primeiro foi preponderante a contribuição do Departamento de Química da antiga Faculdade de Filosofia, Ciências e Letras - FFCL - além de importantes contingentes do Departamento de Física da FFCL, da Faculdade de Farmácia e Bioquímica, do Departamento de Engenharia Química da Escola Politécnica e do Laboratório de Química de Produtos Naturais criado por iniciativa da Fapesp em 1967. Para constituir o Departamento de Bioquímica, além de um pequeno grupo originário da FFCL, aportaram equipes das Faculdades de Medicina, Farmácia e Bioquímica, Medicina Veterinária e Odontologia.

A pesquisa no Instituto, desde a sua fundação, foi basicamente sustentada pela iniciativa individual dos docentes que captaram, em diversas épocas, recursos do $\mathrm{CNPq}$, Capes, Finep, Fapesp, BNDes, STI/MIC, Unesco, OEA, OPAS, Fundaçăo Volkswagen, OMS, Fundaçāo Banco do Brasil, USP/BID entre outros, que permitiram não apenas prover os laboratórios de material e equipamento específicos e assegurar a atualizaçáo constante da biblioteca, mas também possibilitar o intercâmbio científico com a vinda de professores visitantes e o custeio de viagens ao exterior de docentes do Instituto.

Dois programas de envergadura, no entanto, merecem destaque. Um deles, de iniciativa da Fapesp e que abrangeu os vários laboratórios de bioquímica de Săo Paulo, denominado Bioq-Fapesp, beneficiou di- 
retamente o Departamento de Bioquímica, no período de 1972-1976, aproximadamente. Caracterizado pelo rigor na avaliaçáo dos projetos de pesquisa e a correspondente alocação de recursos, cuja gestão coube aos próprios cientistas, funcionou com acompanhamento de assessores internacionais de alto nível, um deles Prêmio Nobel. Através desse programa houve a possibilidade de se conseguir a renovação do equipamento e de se engajar na pesquisa uma nova geração de pesquisadores, catalisando o surgimento de novas lideranças. $O$ outro, do qual participou o Departamento de Química Fundamental, foi patrocinado pelo $\mathrm{CNPq}$, em conjunto com a Academia de Ciências dos Estados Unidos, no período de 1970-1976. Neste, alguns dos mais eminentes cientistas no campo da Química de universidades norte-americanas associaram-se a pesquisadores brasileiros, mantendo como elementos de ligaçăo pesquisadores jovens que, em sua maioria, permaneceram de dois a três anos entre nós. Seis projetos tiveram desenvolvimento no Instituto, possibilitando abrir novas linhas de pesquisa em campos de grande atualidade e levando, em consequiência, à formação de núcleos novos $\mathrm{e}$ à consolidação de outros já existentes.

A associação de Químicos e Bioquímicos no Instituto contrariou a tendência brasileira e mesmo internacional de alocar Departamentos de Bioquímica em Institutos de vocação biológica. Mais natural teria sido agregar o Departamento de Bioquímica ao também recém-constituído Instituto de Ciências Biomédicas. Entretanto, deve-se louvar a percepção dos fundadores que anteviram a crescente afinidade entre a Química e a Bioquímica, tendo em vista que ambas procuram, em última análise, relacionar estrutura molecular com reatividade ou funçáo. A história do desenvolvimento dessas duas ciências mostrou que seus métodos e formas de raciocínio as aproximam, cada vez mais, uma da outra. Apesar dessas características comuns, o IQUSP beneficiou-se sensivelmente da interdisciplinaridade, pois, a ele aportaram docentes com diversas formaçóes como químicos, engenheiros, farmacêuticos, físicos, médicos, biólogos, veterinários e odontólogos.

O sucesso do Instituto deve-se ao fato de que, não obstante as diferentes origens, suas lideranças estavam e estáo imbuídas de iguais propósitos, em razão de uma mentalidade forjada no trabalho experimental, árduo e persistente, e na continuidade da pesquisa, praticada em tempo integral, de modo a torná-la cada vez mais abrangente e profunda com vistas à sua inserção na literatura científica internacional.

Por essas razōes é indubitável, no que concerne ao IQUSP, que a reforma universitária de 1970, criando os Institutos Básicos, promoveu resultados altamente positivos. 


\section{Organização e produção atuais}

O atual Instituto de Química, com 120 professores e um corpo técnico e administrativo de 232 membros, centraliza, no campus da Cidade Universitária, na Capital, o ensino e a pesquisa em Química e Bioquímica. Dispóe de $35.000 \mathrm{~m}^{2}$ de área, onde se distribuem laboratórios didáticos e de pesquisa, um conjunto circular de anfiteatros, salas de aula, escritórios, além do almoxarifado, biotério, oficinas de vidro, mecânica e manutenção em prédio próprio. Recentemente, agregou-se a esse complexo um prédio de $1.700 \mathrm{~m}^{2}$ de Biotecnologia e Química Fina que abrigará, dentre outras atividades, as instalaçóes da Central Analítica, uma iniciativa, em funcionamento desde 1988, destinada a aglutinar equipamentos de grande porte necessários a análises refinadas de substâncias químicas, atividade essa cada vez mais procurada pelas indústrias químicas e pelas demais universidades do país.

A Biblioteca - compartilhada com a Faculdade de Ciências Farmacêuticas -, em prédio novo de $2.500 \mathrm{~m}^{2}$, foi classificada pelo Conselho Nacional de Desenvolvimento Científico e Tecnológico como Biblioteca principal de Química do país: conta com um acervo, entre livros e periódicos, de $\mathbf{6 8 . 3 9 4}$ volumes tombados e cerca de $\mathbf{8 0 . 0 0 0}$ fascículos sem encadernação. As publicaçóes periódicas do acervo perfazem o total de 2.769 títulos, dos quais 816 são correntes. Desse total 574 são subscriçóes adquiridas e 262 permutados ou doados. A Biblioteca é, ainda, depositária de aproximadamente 55.000 patentes americanas em microfichas, e é muito frequientada não só pelos docentes e estudantes mas também por profissionais da indústria química.

No âmbito da graduação, registrando média semestral de $\mathbf{2 . 8 0 0}$ matrículas por disciplinas, o IQUSP ministra disciplinas obrigatórias para 18 currículos diferentes de 13 Unidades da USP sediadas no $\mathrm{cam}$ pus da Capital, além de atender cerca de 400 alunos matriculados sob sua responsabilidade em cursos que levam à formação de bacharéis em Química, licenciados em Química e Químicos com atribuiçóes tecnológicas. No âmbito da pós-graduação, com aproximadamente 400 alunos regularmente matriculados em cursos de mestrado e doutoramento, credenciados pelo Conselho Federal de Educaçáo, forma professores universitários e pesquisadores em Química e Bioquímica.

Desde a sua criação, em 1970, até o final de 1993, registra vigorosa produção científica, expressa em 2108 publicaçōes, computando-se somente as publicaçóes completas em revistas de circulação internacional e 1034 títulos de pós-graduação expedidos: 460 mestrados e 574 doutoramentos. 
A grande explosão de conhecimentos e a crescente interdisciplinaridade com outras ciências torna impossível uma descrição pontual das atividades de dezenas de grupos de pesquisa no IQUSP. Parece-nos mais útil descrever os principais objetivos da Química moderna e a sua relaçăo com as atividades de pesquisa na instituição.

\section{Pesquisa e pós-graduação}

Grande ênfase foi dada à vinculação da pós-graduação com a pesquisa, na conviç̧ão de que náo pode existir verdadeira pós-graduaçáo sensu stricto sem atividade de investigação e é essencialmente da qualidade desta que se afere o nível global. Pesquisa e pós-graduaçáo têm caminhado juntas e se beneficiado reciprocamente, refletindo-se este fato de maneira marcante na produçáo científica do Instituto.

O desenvolvimento da investigaçăo moderna em Bioquímica levou o Departamento a concentrar-se principalmente em três grandes áreas do conhecimento biológico: bioquímica, biologia celular e biologia molecular. Os grupos do Departamento - aproximadamente 20 dedicam-se ao estudo de fotobiologia no escuro; bioquímica, biologia molecular e diferenciação em microorganismos, insetos e vertebrados; expressão gênica; fatores de crescimento; síntese de peptídios; catálise micelar; estrutura de lipídios complexos; toxicologia de policlorados; modelos de membrana, dentre outros, podendo-se aglutinar essas linhas em quatro grandes correntes: estrutura e funçáo de proteínas; controle da expressão gênica; espécies reativas em Biologia; modelos e membranas. Para a execução de seus trabalhos os professores recorrem às técnicas mais modernas oferecidas pela engenharia genética bem como a procedimentos analíticos sofisticados como cromatografia líqüida de alta pressão, ressonância paramagnética eletrônica, eletroforese de campo pulsado, ultracentrifugaçáo entre outras.

O Departamento de Química Fundamental tem o dobro de docentes do Departamento de Bioquímica e atua em diversas linhas da Química moderna. Um dos objetivos centrais da Química é a compreensão do fenômeno da reatividade química. A conseqüência da compreensão detalhada dos mecanismos que controlam a reatividade em nível molecular seria o desenvolvimento de novos catalisadores e novos métodos de síntese, bem como o planejamento de novos fármacos, além de fornecer subsídios moleculares para a compreensão de disfunçóes biológicas que determinam as doenças. Outra vertente na Química moderna diz respeito ao desenvolvimento de novos materiais com propriedades específicas visando a aplicaçóes nas áreas de polímeros condutores, polímeros biocompatíveis e supercondutores. Nesse campo é 
fundamental controlar a pureza das diversas substâncias, o que é possível com o desenvolvimento e a aplicação de técnicas cromatográficas, emissáo atômica, termoanálise e técnicas eletroanalíticas, campos intensamente trabalhados no Instituto. Métodos de análise para algumas substâncias chegam a detectar picogramas (um trilionésimo do grama) com contaminantes na faixa de femtogramas (um quatrilionésimo do gra$\mathrm{ma})$.

Para que esses grandes objetivos sejam alcançados, uma condição essencial deve ser satisfeita: o conhecimento detalhado da estrutura molecular e, em alguns casos, da estrutura supramolecular. Para isso, o IQUSP dispóe de equipamentos denominados espectrômetros - de ressonância magnética nuclear, paramagnética eletrônica, Raman acoplado a laser, de massa - que ajudam a conhecer a disposição espacial dos átomos numa molécula. Esse trabalho exige também o conhecimento das energias envolvidas nas ligações químicas o que permite deduzir quais os melhores pontos de rompimento da molécula ou de sua reatividade.

Pode-se ainda compreender porque certas moléculas têm a sua reatividade alterada na presença de luz - o objeto da fotoquímica que, entre outras abordagens, procura entender o mecanismo de uma reaçáo química vital para o planeta - a fotossíntese - modelo ideal de produçăo de energia eficiente e não poluente.

$\mathrm{Na}$ tentativa de entender mais detalhadamente a reatividade química, os pesquisadores passaram a utilizar lasers que podem ser sintonizados para se colocar a energia luminosa em determinadas ligações químicas da molécula, tornando possível reações seletivas que dão origem ao produto desejado. Esse velho sonho dos alquimistas, ainda longe de ser realizado, alcança resultados impressionantes. O IQUSP possui lasers pulsados acoplados a espectrômetro de ressonância ciclotrônica de íons utilizado nessa área, conhecida como Dinâmica Química.

Ao longo das últimas décadas, métodos computacionais para o cálculo de propriedades moleculares têm se tornado crescentemente importantes. Os cálculos baseiam-se em modelos teóricos derivados da Mecânica Quântica, cujos princípios regem o comportamento de átomos e moléculas. A existência de grupos de pesquisa nesta área no IQUSP somente tornou-se possível graças à existência de recursos computacionais de grande porte na Universidade e de facilidades computacionais menores na instituiçáo.

Extensão de serviços à sociedade

O IQUSP mantém-se aberto às interaçōes com a Indústria. Criou 
a Central Analítica, que executa análises sofisticadas para as empresas e para as demais universidades brasileiras. Em 1993, somente na área de Ressonância Magnética Nuclear, a Central Analítica atendeu a 436 pedidos de empresas, outras universidades e institutos de pesquisa, além dos 4103 espectros solicitados pelos cientistas do próprio IQUSP. $O$ laboratório de microanálises que quantifica carbono, hidrogênio, nitrogênio, enxofre, cloro e bromo atendeu, em 1993, a 1085 pedidos de empresas e universidades e 2305 pedidos de professores do IQUSP: No total dos serviços prestados, a Central Analítica executou, em 1993, 40 análises por dia. Além disso, alguns grupos de pesquisa, por meio de cursos promovidos em conjunto com as sociedades representativas da Química e da Bioquímica, tentam atualizar o conhecimento do maior número possível de profissionais da empresa privada bem como trocam informaçōes importantes para ambas as partes.

\section{Atividades de organização do ensino}

Finalmente, o IQUSP mantém alguns grupos dedicados ao ensino da Química seja ensinando estudantes de pós-graduaçáo a ensinar, seja reciclando de forma sistemática profissionais do ensino secundário, ou ainda estudando e experimentando propostas - com elaboraçăo de manuais para professores e estudantes - que promovam a modernizaçáo do currículo, integrando-o cada vez mais ao perfil exigido pela indústria, sem descurar-se da formaçáo básica requerida por uma ciência exata, não só para incutir no jovem o maior número de elementos de racionalidade em sua formação como também proporcionar aos estudantes meios para que se desempenhem a contento em face de problemas de resolução desconhecida.

\section{Conclusões}

Em resumo, na Bioquímica, a preocupação fundamental dos diversos grupos de pesquisa é relacionar a estrutura molecular com a função biológica. As moléculas podem ser pequenas ou grandes e estas chegam a ter tamanhos de milhóes de peso molecular, podendo até ser visíveis ao microscópio eletrônico. Na Química, a preocupaçáo é relacionar a estrutura com a reatividade, havendo grupos preocupados com métodos analíticos e sintéticos, métodos extrativos de produtos naturais, análise de poluentes e purificação e determinaçáo de estruturas moleculares, trabalhando com substâncias orgânicas e inorgânicas.

Não caberia neste simples resumo, destinado a náo-especialistas, proceder a relato sobre linhas específicas de abordagem experimental, por ser tedioso e longo. Pelo exposto, entretanto, vê-se que a Química 
moderna, praticada nos laboratórios de pesquisa básica ou aplicada do IQUSP, está bastante distante da noçáo que cada um de nós tem da Química, tal qual nos foi ensinada no curso secundário. Ela está longe de ser uma ciência fenomenológica ou empírica. O IQUSP, através de suas atividades de ensino, pesquisa e extensão tem, mesmo com as dificuldades por que passa a Universidade brasileira, correspondido às expectativas como um dos mais importantes centros da Iberoamérica nas áreas de Química e Bioquímica.

Waltar Colli é professor de Bioquímica, diretor do Instituto de Química da USP e membro do Conselho Deliberativo do IEA-USP. Este resumo foi escrito com inestimáveis subsídios dos professores Paulo Sérgio Santos, Hernan Chaimovich, Omar El Seoud, Ivano Gutz, Joāo Valdir Comasseto, Massayoshi Yoshida e Paschoal Ernesto Américo Senise. 